\title{
The Catalytic Thermo-oxidative Decomposition of Glimepiride
}

\section{Najam US Sahar Riyaz ${ }^{1}$, Ismail Badran ${ }^{1 *}$}

\section{${ }^{1}$ Department of Chemistry and Earth Sciences, Qatar University, P.O. Box 2713, Doha, Qatar}

*ibadran@qu.edu.qa

\section{ABSTRACT}

In this study, the thermal decomposition of glimepiride is analysed in the presence of $\mathrm{N}_{2}$ and $\mathrm{O}_{2}$ and the presence of various metal oxide catalysts. The analysis was conducted using TGA. From the results obtained, in the presence of $\mathrm{N}_{2}$ there were two significant mass losses while an additional mass loss was observed in the presence of oxygen. The mechanism for decomposition is also proposed. Vanadium oxide was the most efficient at lowering the temperature required for thermal decomposition. The results of this study pave way for future work into purifying wastewater from pharmaceuticals via adsorption.

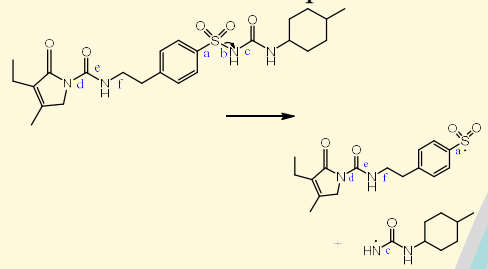

First step proposed for the decomposition of Glimepiride under $\mathrm{N}_{2}$ which accounts for the first significant mass loss

\section{RESULTS}



Isoconversional Kinetics Analysis (Friedman and KAS) fo thermal decomposition of glimepiride in $\mathrm{O}_{2}$ between 210-

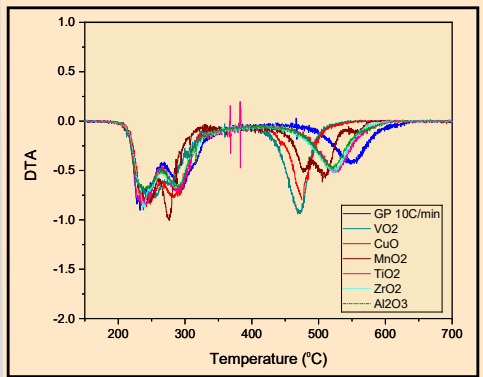

DTA curve for thermal decomposition of glimepiride in the presence of various catalysts in $\mathrm{O} 2$.
METHODOLOGY
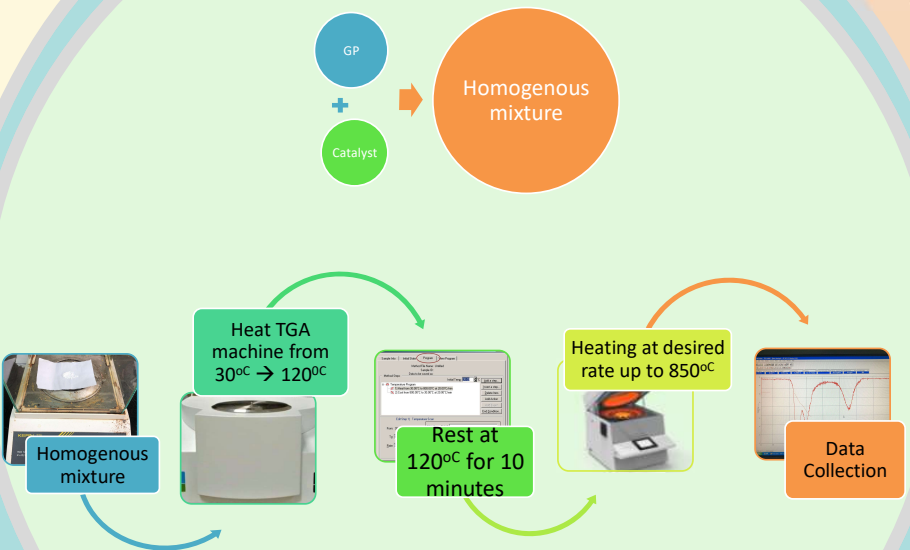

The results show:

The activation energy for the first significant mass loss, which is also shown in the middle, is calculated to be approximately $170 \mathrm{~kJ} / \mathrm{mol}$

The activation energy for the decomposition under $\mathrm{O}_{2}$ is higher as compared to $\mathrm{N}_{2}$

The catalysts significantly lowered the activation energy for decomposition under $\mathrm{O}_{2}$, as per the DTA graph, $\mathrm{VO}_{2}$ has the most effective catalytic performance.

\section{THE CONCEPT}

Pharmaceutical and Personal Care Products (PPCPs) in wastewater are one of the most significant causes for concern regarding health. Wastewater treatment plants (WWTPs) fail to purify the water in a sufficient manner, thus there is a pressing need for an effective mechanism to metabolise the PPCPs present in wastewater. Glimepiride (Amaryl) is commonly used to treat type 2 diabetes. It is not completely metabolized by the human body and is thus found in wastewater. This drug is proven to be harmful to marine and aquatic life as well.

\section{REFERENCES}

- Badran, Ismail, et al. Thermochimica Acta 694 (2020): 178797.

- Badran, Ismail, et al. Environmental Science and Pollution Research 28.12 (2021): 14694-14706.

\section{ACKNOWLEDGEMENT}

This project is supported by the student grant number QUST-1CAS-2020-3. The authors are thankful to the Department of Chemistry and Earth Sciences, Qatar University.
BENEFITS TO OATAR

Qatar has a significant amount of wastewater which is recycled after purification for multiple everyday uses, thus the findings of this study provide insight into how the pollutants present in wastewater can be decomposed in a manner which will result in

Structure of Glimepiride

\section{CONCLUSION}

Under $\mathrm{N}_{2}$ there are two significant mass loss steps and under $\mathrm{O}_{2}$ a third one is added for the oxidation step of the drug. Using theoretical calculations, the bond energies for the decomposition mechanism were determined, which were in line with the experimental values. The results of this study are important for future work of removing glimepiride from polluted water The findings can also be used to determine how the decomposition products can be sed for useful industrial materials.

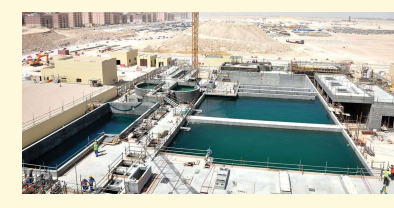

Wastewater Treatment Plant in Qatar 